\title{
REGENERACIÓN DE PLANTAS IN VITRO DE Peumus boldus Mol. (BOLDO) MEDIANTE ORGANOGÉNESIS DE BROTES EPICÓRMICOS DE ÁRBOLES MADUROS
}

\author{
Koch, $\mathrm{L}^{10}$;; González, $\mathrm{J}^{10}$.; Benedetti, $\mathrm{S}^{11}$. y Molina, M. $\mathrm{P}^{10}$
}

\section{RESUMEN}

El Instituto Forestal de Chile (INFOR), a través de diferentes líneas de trabajo, ha desarrollado investigaciones que han incluido la especie boldo (Peumus boldus Mol.), respecto de su silvicultura y manejo, principios activos contenidos en sus hojas y procesos de obtención de productos químicos.

Boldo es una especie nativa y endémica de Chile representativa del bosque esclerófilo, presente en formaciones naturales de amplia distribución en la zona central y sur del país. Su valor radica principalmente en sus componentes activos, entre los que se destaca una serie de alcaloides, siendo la boldina el componente más conocido.

Mediante micropropagación por vía organogénica se pretende desarrollar un protocolo de regeneración in vitro de árboles de Peumus boldus Mol seleccionados por su alto contenido de boldina, previo análisis químico. Se consideró como fuente de explantes brotes epicórmicos. Los resultados indican que es posible regenerar plantas completas mediante técnicas de micropropagación.

Palabras clave: Boldo, micropropagación, brotes epicórmicos.

\section{ABSTRACT}

The Chilean Forestry Institute (INFOR) has developed through different work lines research on Boldo (Peumus boldus $\mathrm{Mol}$ ), regarding to its silviculture and management, the active principles contained in its leaves and also on processes to obtain these chemical products.

Boldo is a Chilean native and endemic species representative of the sclerophyll forest present as natural formations in a wide distribution in central and southern areas of the country. Its value is based mainly on its active components, including alkaloids, as boldine the best known one.

Organogenic micro propagation is applied in trying to develop an in vitro regeneration protocol for boldo's trees selected, through previous chemical analysis, for their high boldine content. Epicormic buds were considered as a source of explants. The results indicate that it is possible to regenerate whole plants by means of micropropagation techniques.

Keywords: Boldo, micropropagation, epicormics shoots

\footnotetext{
10 Investigadores, Instituto Forestal. Sede Bio Bio, Concepción. Ikoch@infor.cl

11 Investigadora. Unidad de Transferencia Tecnológica, Instituto Forestal. Santiago.
} 


\section{INTRODUCCIÓN}

Boldo (Peumus boldus Mol) es una especie endémica de Chile, representativa de los bosques esclerófilos. Su distribución geográfica va desde la región de Coquimbo hasta la región de Los Lagos, con mayor presencia en las regiones centrales, Maule a Bio Bio. Su límite norte está

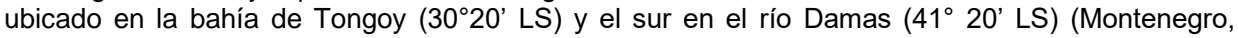
2000; Espic, 2007).

Su valor radica principalmente en sus componentes activos, entre los que se destaca una serie de alcaloides, siendo la boldina el componente más conocido como protector hepático, por esta razón se ha visto un creciente interés por su follaje. El mercado está orientado a satisfacer las necesidades de la industria alimentaria y farmacéutica.

Existe poco rejuvenecimiento de la especie en poblaciones naturales, lo que puede estar afectado por factores ambientales adversos, tales como la exposición a prolongados periodos secos o al pastoreo y por la dificultad que presentan las semillas en la germinación, las que en general requieren un largo período para que puedan emerger como plántulas (San Martín y Doll, 1998; Voguel et al., 2005).

Hartmann y Kester (1990) señalan que, en los casos de especies cuya germinación es escasa o que presentan largos períodos para este proceso, se prefiere una propagación asexual mediante estacas para conseguir individuos juveniles de importancia productiva. Boldo, presenta limitaciones en cuanto a su cultivo a través de propagación vegetativa y sexuada, como bajas tasa de enraizamiento de estacas. Jeldres (1998) evalúa en una primera instancia el comportamiento de esta especie a diferentes concentraciones de AIB con estacas provenientes de individuos jóvenes y adultos de formaciones naturales ( 7 a $13 \mathrm{~cm}$ de DAP y 2 a $5 \mathrm{~m}$ de altura), y dos épocas de colecta (invierno y primavera), obteniendo bajos porcentajes de supervivencia (no mayor a $20 \%$ ).

La organogénesis somática es una alternativa muy útil cuando no se obtienen buenos resultados mediante enraizamiento de estacas o se requiere aumentar la tasa de multiplicación, o bien en el caso de árboles adultos para revertir y mantener su juvenilidad fisiológica (McComb y Bennet, 1986). También es una técnica adecuada para la conservación en un estado juvenil de genotipos forestales, mediante la utilización de técnicas de crecimiento retardado.

Uno de los aspectos más difíciles de abordar en la organogénesis de árboles adultos es la introducción de material aséptico a condiciones in vitro. En general, la desinfección de brotes colectados directamente en terreno es difícil, debido a la gran cantidad de contaminación tanto exógena como endógena presente en este material (De Fossard et al., 1977).

Según Le Roux y Van Staden (1991) es virtualmente imposible esterilizar este material sin dañar severamente el tejido de los explantes iniciales. La edad del material es un factor importante que condiciona el establecimiento de cultivos asépticos (Grewal et al., 1980), idealmente este debiera tener muchas de las cualidades encontradas en brotes juveniles, por esta razón es común emplear técnicas de pre-tratamiento del material adulto, con el fin de obtener explantes iniciales adecuados para el cultivo in vitro.

Se han establecido cultivos asépticos de árboles adultos, a partir de rebrotes de tocón (Furze y Cresswell, 1985), brotes de injertos (Franclet y Boulay, 1982; Durand-Cresswell et al., 1982; Goncalves, 1980), brotes epicórmicos (Oller et al. 2004, Ikemori, 1987), brotes de estacas enraizadas y brotes de ramas pretratadas, en especies caducifolias (Sabja et al., 2005; Ortiz et al., 2006).

El presente trabajo, desarrollado en el laboratorio de Micropropagación de INFOR, tiene por objetivo generar un protocolo efectivo de micropropagación de material adulto de boldo a través de inducción de brotes epicórmicos, con el fin de obtener plantas micropropagadas de individuos sobresalientes en base a variables fenotípicas y químicas de interés comercial, en biomasa aérea hojas, corteza y madera, para contar con material selecto superior. 


\section{METODOLOGÍA}

\section{Material Vegetal}

El material vegetal se obtuvo de explantes provenientes de brotes epicórmicos de 3 árboles adultos localizados en las dependencias de INFOR, San Pedro de la Paz, Región del Bio Bio (Coordenadas - 36.8491 y -73.1327). A comienzos de la temporada de verano del año 2016 , se colectaron trozos de ramas de estos árboles (Genotipos), los cuales fueron codificados como clon 1 (C1), clon 2(C2) y clon 3 (C3), los trozos de rama tenían 2 a $4 \mathrm{~cm}$ de diámetro y 30 a $35 \mathrm{~cm}$ de longitud aproximadamente. Estas muestras, fueron llevadas en cajas térmicas para evitar la deshidratación del material al Laboratorio de Micropropagación Forestal (LMF). Las muestras fueron lavadas con detergente líquido comercial (Quix®) para eliminar tejidos superficiales muertos o envejecidos, mediante la utilización de una escobilla pequeña, posteriormente las varetas fueron instaladas en frascos limpios con agua destilada y perlita previamente esterilizados en autoclave a $121^{\circ} \mathrm{C}$ y $0,1 \mathrm{MPa}$ de presión, durante 30 minutos, el extremo superior de la rama fue recubierto con un sellante comercial de poda, Podastik Plus ${ }^{\circledR}$.

Posteriormente, los trozos de ramas fueron llevados a una sala acondicionada utilizando un humificador para aumentar la humedad relativa (HR) y así estimular la formación de brotes epicórmicos. El material permaneció en una sala climatizada por aproximadamente 50 días, bajo condiciones controladas de temperatura $22 \pm 2^{\circ} \mathrm{C}$, HR $70 \%-80 \%$ y un fotoperíodo de $16 / 8$ horas luz/oscuridad, respectivamente. Durante ese tiempo se evaluó la emergencia, el número y altura de brotes epicórmicos generados por los diferentes genotipos, estas variables fueron tomadas como datos cuantitativos y utilizadas para comparar los genotipos según la metodología presentada en la sección Análisis Estadístico.

\section{Desinfección y Cultivo de Brotes}

Para el establecimiento de los cultivos in vitro se seleccionaron brotes desarrollados con una longitud de entre 2 a $9 \mathrm{~cm}$, con al menos 3 yemas de crecimiento y 2 pares de hojas expandidas (Figura 1), a los cuales se les realizó la desinfección superficial utilizando el siguiente protocolo, remojo en una solución de hipoclorito de sodio $(\mathrm{NaOCl})$ al $10 \%$, durante 5 minutos, seguido de cuatro enjuagues (aclareos) de 10 minutos cada uno, con agua destilada estéril (ADE), posteriormente un remojo de 30 minutos en una solución antioxidante, compuesta por ácido cítrico y ácido ascórbico en concentraciones al 1:1 de $500 \mathrm{mg} / \mathrm{L}$. Se evaluó la tasa de brotes contaminados (TBC), considerando contaminación fúngica y bacteriana, y tasa de brotes oxidados (TBO), para la cual se considera presente cuando el brote tiene una oxidación sobre el $50 \%$ de la superficie, estos parámetros fueron recogidos porcentualmente por cada genotipo.

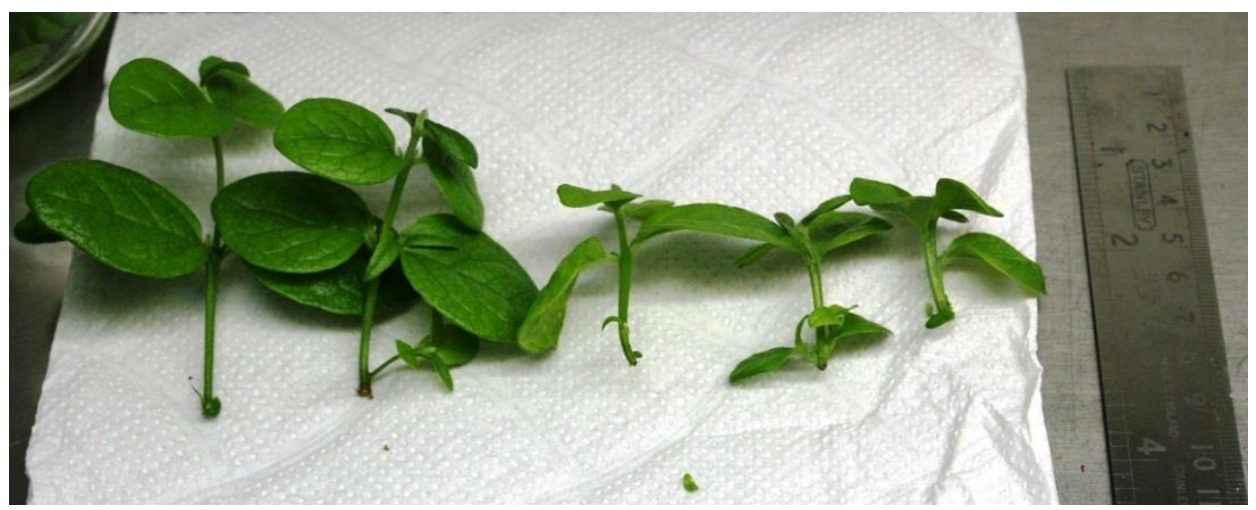

Figura $\mathrm{N}^{\circ} 1$

BROTES REJUVENECIDOS OBTENIDOS A TRAVÉS DE LA INDUCCIÓN DE BROTES EPICÓRMICOS EN TROZOS DE RAMAS DE ÁRBOLES ADULTOS 


\section{Medios y Cultivo del Material}

Se utilizaron diferentes formulaciones (tratamientos) del medio MS (Murashige y Skoog, 1962) según las diferentes etapas de organogénesis; establecimiento, multiplicación, elongación y enraizamiento. Se utilizó un brote por frasco snap al cual se le adicionó entre 3 a $5 \mathrm{ml}$ de medio de cultivo fresco según la etapa.

Para la etapa de establecimiento se cortó a cada brote una pequeña porción de la base y se colocó en el medio nutritivo Murashige y Skoog médium (MS) sin hormonas de crecimiento ni antioxidantes suplementarios, cada 20 días fueron repicados sin subdividir el tejido. Los brotes cultivados fueron mantenidos en cámara de crecimiento bajo condiciones controladas de temperatura a $22 \pm 2 \stackrel{\circ}{ } \mathrm{C}$, y bajo una condición de fotoperíodo de 16/8 horas luz/oscuridad respectivamente.

\section{Multiplicación de Brotes}

Para la etapa de multiplicación, tal como se aprecia en el Cuadro $N^{\circ} 1$, todos los medios nutritivos fueron preparados usando $0,07 \%$ de agar bacteriológico y $0,2 \%$ de sacarosa, el $\mathrm{pH}$ fue ajustado en $5,7 \pm 0,05$ antes de su esterilización en autoclave a $121^{\circ} \mathrm{C}$ y $0,1 \mathrm{MPa}$, durante 20 minutos.

El material sin contaminación u oxidación obtenido durante la etapa del establecimiento, fue traspasado con una alta frecuencia a medio fresco de multiplicación, con un período máximo de 28 días entre cada repique, esto con el fin de mitigar los intensos procesos de oxidación y necrosis observados en la especie (Koch et al., 2016).

A medida que se establecieron los cultivos, eventualmente se adicionó al medio de cultivo polivinilpirrolidona (PVP) en concentraciones de $800 \mathrm{mg} / \mathrm{L}$ y se reemplazó por el gelificante Gelrite ${ }^{\circledR}$ a $0,025 \%$ con el fin de disminuir la oxidación de los tejidos.

En esta etapa, los explantes fueron cultivados en frascos de vidrio de $500 \mathrm{cc}$ de capacidad, tapados con film de polietileno, los cultivos se mantuvieron en la sala de crecimiento del LMF, bajo condiciones controladas de temperatura $22 \pm 2{ }^{\circ} \mathrm{C}$ de temperatura y fotoperiodo $16 / 8$ horas de luz/oscuridad, respectivamente. Las variables número de brotes nuevos (NBN) y número de hojas nuevas $(\mathrm{NHN})$, fueron utilizadas para comparar los diferentes tratamientos.

\section{Cuadro $\mathrm{N}^{\circ} 1$}

FORMULACIÓN QUÍMICA DE LOS 4 MEDIOS DE CULTIVO O TRATAMIENTOS PARA LA ETAPA DE MULTIPLICACIÓN IN VITRO

\begin{tabular}{|l|c|c|c|c|c|}
\hline Compuestos & Unidad & Control & T1 & T2 & T3 \\
\hline Sales Macronutrientes (MS) & - & Completo & Completo & Completo & Completo \\
\hline BAP (6-Benzilamino-Purina) & $\mathrm{Mg} / \mathrm{L}$ & 0 & 0,25 & 0,5 & 0,75 \\
\hline ANA (Ácido 1-Naftalenacético) & $\mathrm{Mg} / \mathrm{L}$ & 0 & 0,01 & 0,01 & 0,01 \\
\hline Pantotenato de Calcio & $\mathrm{Mg} / \mathrm{L}$ & 0 & 1,0 & 1,0 & 1,0 \\
\hline Hidrolizado de Caseína & $\mathrm{Mg} / \mathrm{L}$ & 0 & 75 & 75 & 75 \\
\hline Sacarosa & $\%$ & 0,2 & 0,2 & 0,2 & 0,2 \\
\hline Agar/Gelrite & $\%$ & 0,07 & $0,07 / 0,025$ & $0,07 / 0,025$ & $0,07 / 0,025$ \\
\hline PVP (Polivinilpirrolidona) & $\mathrm{Mg} / \mathrm{L}$ & 0 & 800 & 800 & 800 \\
\hline
\end{tabular}




\section{Enraizamiento de Brotes}

El medio base utilizado en los ensayos de enraizamiento fue el medio nutritivo MS, con los macronutrientes reducidos a la mitad ( $1 / 2 \mathrm{MS})$, y nitratos reducidos a un cuarto ( $1 / 4 \mathrm{MS})$, complementado con $0,15 \%$ de sacarosa y $0,07 \%$ de agar. Se probaron tres tratamientos de enraizamiento, donde se evaluó la aptitud de enraizamiento de los brotes in vitro de boldo respecto a distintas dosis de la auxina ácido indol-3-butírico (IBA).

El material ensayado correspondió solamente al clon 3 (C3), ya que solo este mostró un desarrollo radicular, para ello se seleccionaron brotes elongados sanos, vigorosos, homogéneos, y que tuvieran un tamaño de al menos $4 \mathrm{~cm}$, como los que se muestran en la Figura $\mathrm{N}^{\circ} 2$. Para los diferentes tratamientos se utilizaron medios de cultivos con concentraciones de IBA: de $0 ; 0,5 ; 1 ; 2$ y $3 \mathrm{mg} / \mathrm{L}$.

Se dispusieron diez repeticiones por cada uno de los tratamientos, el ensayo fue evaluado desde los 7 hasta los 60 días desde su inicio. Los explantes una vez cultivados permanecieron en oscuridad absoluta durante 7 días, luego fueron trasladados bajo condiciones controladas de temperatura $22 \pm 2{ }^{\circ} \mathrm{C}$ y fotoperiodo de $16 / 8$ horas luz/oscuridad, respectivamente. Se evalúo la capacidad de enraizamiento de los brotes como el número y longitud de raíces nuevas (NRN y LRN, respectivamente).

\section{FORMULACIÓN QUÍMICA DE LOS 3 MEDIOS DE CULTIVO (TRATAMIENTOS) PARA LA ETAPA DE ENRAIZAMIENTO IN VITRO}

\begin{tabular}{|l|c|c|c|c|c|}
\hline Compuestos & Unidad & Control & T1 & T2 & T3 \\
\hline Macronutrientes & - & $1 / 2$ & $1 / 2$ & $1 / 2$ & $1 / 2$ \\
\hline Nitratos & - & $1 / 4$ & $1 / 4$ & $1 / 4$ & $1 / 4$ \\
\hline IBA (Ácido Indol-3-butírico) & $\mathrm{Mg} / \mathrm{L}$ & 0 & 1 & 2 & 3 \\
\hline Sacarosa & $\%$ & 0,15 & 0,15 & 0,15 & 0,15 \\
\hline Agar & $\%$ & 0,07 & 0,07 & 0,07 & 0,07 \\
\hline
\end{tabular}
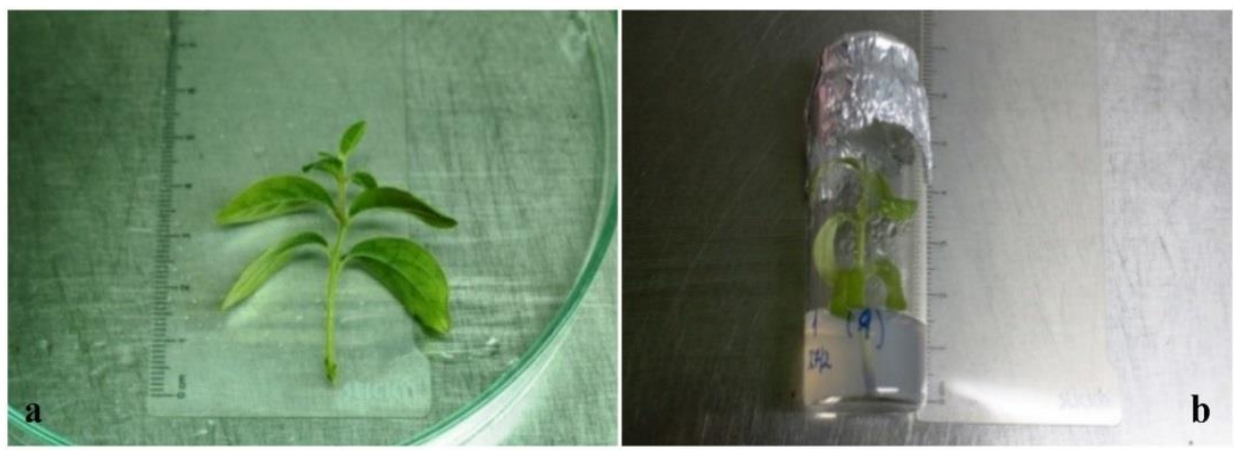

Figura $\mathrm{N}^{\circ} 2$

CARACTERÍSTICA DE BROTES MODELO DE PLANTAS IN VITRO, UTILIZADOS EN LA ETAPA DE ENRAIZAMIENTO (a). BROTE IN VITRO CULTIVADO EN MEDIOS DE ENRAIZAMIENTO (b) 


\section{Aclimatación de Plantas}

Las plantas in vitro enraizadas fueron traspasadas bajo cámara de flujo laminar a envases plásticos herméticos que contenían una mezcla de sustrato compuesto por turba y perlita en una proporción de 2:1, respectivamente, previamente esterilizada en autoclave a $121^{\circ} \mathrm{C}$ y 0.1 $\mathrm{MPa}$, durante 30 minutos.

Esta etapa requiere precaución, ya que el cambio de medio puede producir estrés en las vitroplantas o bien pueden contaminarse los explantes perdiendo gran parte del material vegetal. El sustrato fue enriquecido mediante la adición de medio nutritivo líquido (sin gelificante) MS, reducido a la mitad ( $1 / 2 \mathrm{MS})$ y sin sacarosa, durante un período de 12 semanas. Durante este tiempo las plantas se fueron mantenidas bajo condiciones controladas de temperatura $22 \pm 2{ }^{\circ} \mathrm{C}$ y fotoperiodo de 16/8 horas luz/oscuridad, respectivamente.

\section{Análisis Estadísticos}

Los datos fueron recogidos periódicamente como variables numéricas durante la evaluación (días) en las diferentes etapas de la micropropagación, se realizaron análisis de varianzas (ANOVA) para determinar las diferencias significativas entre los diferentes tratamientos de generación de brotes epicórmicos, multiplicación y enraizamiento, los supuestos de normalidad y homogeneidad de varianza, fueron medidos mediante las pruebas de Shapiro-Wilk $(\alpha=0.05)$ y Levene $(\alpha=0.05)$, en algunos casos se trasformaron las variables para ajustar normalidad.

Los mejores tratamientos fueron seleccionados mediante la prueba post hoc, Tukey HSD $(\alpha=0.05)$. Todos los análisis y gráficos se realizaron con el software R-Project versión 3.5.1(R Core Team, 2018).

\section{RESULTADOS}

\section{Colecta del Material}

El material vegetal utilizado fue colectado según los parámetros definidos en la metodología. En el Cuadro $\mathrm{N}^{\circ} 3$ se detalla para cada clon el resultado de la colecta de material.

Cuadro $\mathrm{N}^{\circ} 3$

ANTECEDENTES DE LAS MUESTRAS

PARA PRODUCCIÓN DE BROTES EPICÓRMICOS

\begin{tabular}{|c|c|c|c|c|}
\hline ID & Clon & $\mathbf{N}$ & $\begin{array}{c}\text { DP } \\
(\mathbf{c m})\end{array}$ & $\begin{array}{c}\text { TP } \\
(\mathbf{c m})\end{array}$ \\
\hline 1 & 1 & 10 & 3,0 & 29,6 \\
\hline 2 & 2 & 11 & 2,7 & 34,3 \\
\hline 3 & 3 & 10 & 2,7 & 35,8 \\
\hline
\end{tabular}

$\mathrm{N}$ : Numero de ramas DP: Diámetro promedio TP: Tamaño promedio

\section{Generación de Brotes Epicórmicos}

Usando las varetas colectadas previamente se indujo la generación de brotes epicórmicos, los cuales se desarrollan desde yemas meristemáticas, también denominadas yemas durmientes, las cuales se sitúan en posiciones axiles o bajo la corteza durante el crecimiento del árbol (Figura $\mathrm{N}^{\circ} 3 \mathrm{a}$ ).

Los brotes generados a partir de estas yemas presentan un crecimiento extremadamente rápido porque son fisiológicamente más jóvenes que los otros (Yara, 1987; Borges et al., 2004) (Figura 3b). Los brotes siempre se desarrollan en la zona inferior de los nudos de las ramas (Figura $\left.N^{\circ} 3 c\right)$. 
Una secuencia temporal de la emergencia de los brotes epicórmicos, a partir del material colectado desde los árboles de prueba, se muestra en la Figura $N^{\circ} 3$. Como se aprecia, los brotes epicórmicos presentan una morfología que se asemeja a un estado juvenil de los tejidos en $P$. boldus, lo cual los hace especialmente adecuados para la micropropagación por poseer propiedades del estado juvenil del árbol.

La utilización de este tipo de material puede realzar la multiplicación y enraizamiento in vitro, de árboles adultos, tal como ha sido reportado tempranamente en especies forestales (Fink, 1983; Ikemori, 1987; Yara, 1987; Sánchez et al., 1996).
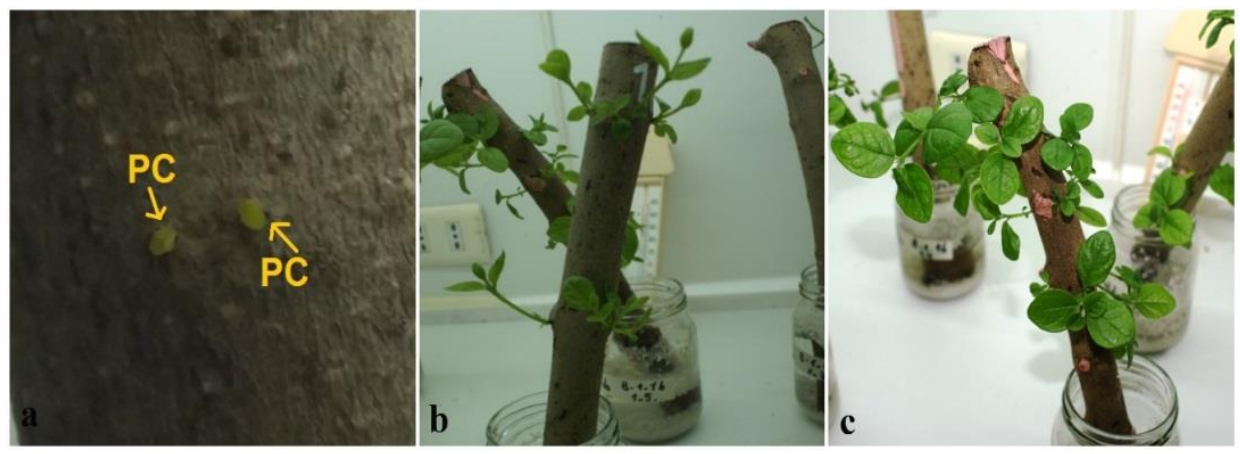

PC: Puntos de crecimiento de los brotes (a).

Se observan fases aproximadamente de 15, 30 y 45 días posteriores a la inducción de brotación (b) y (c).

\section{Figura $N^{\circ} 3$}

BROTES EPICÓRMICOS GENERADOS DESDE TROZOS DE RAMAS DE ÁRBOLES

Se logró obtener brotes epicórmicos del material obtenido de los 3 árboles dentro del tiempo esperado (Figura $\mathrm{N}^{\circ} 3 \mathrm{c}$ ). La emergencia de los brotes, ocurrió alrededor de los 20-30 días.

El número de brotes generados depende de los puntos de crecimiento que tenga la vareta inicial, el desarrollo inicial de estos brotes siempre comienza en pequeños grupos de células del parénquima en la corteza o en los radios del floema dilatados, que se desdiferencian, transformándose en meristemáticos nuevamente mediante subdivisiones repetidas (Fink, 1983).

En el presente estudio de boldo, el clon que exhibió tempranamente la mayor producción de brotes correspondió al clon 1 (C1), mientras que, en los clones de menor desempeño, clones 2 (C2) y 3 (C3) la producción de brotes se produjo en lapsos mayores de tiempo, llegando a registrarse hasta 45 días (Figura $\mathrm{N}^{\circ} 4$ ).

En cuanto a la calidad de los brotes, se midió la altura de algunos brotes, encontrando una alta heterogeneidad en los diferentes genotipos, siendo nuevamente el $\mathrm{C} 1$ el que posee brotes de mayor tamaño $(F=7,84, p$-valor=0,002), por lo tanto, se podría suponer que la capacidad de desarrollar brotes epicórmicos depende del genotipo (Figura $\mathrm{N}^{\circ} 5$ ).

Sin embargo, en otras especies se ha reportado que tanto el número y calidad de brotes epicórmicos formados se encuentran condicionados por la época de colecta del material, el lugar dentro del árbol de donde se colecta y del estado fitosanitario (Hernández et al., 2003), por lo que es posible que el bajo o nulo desempeño de algunos clones pueda ser mejorado al colectar material en otra época del año o bien tomando en consideración estas variantes. 


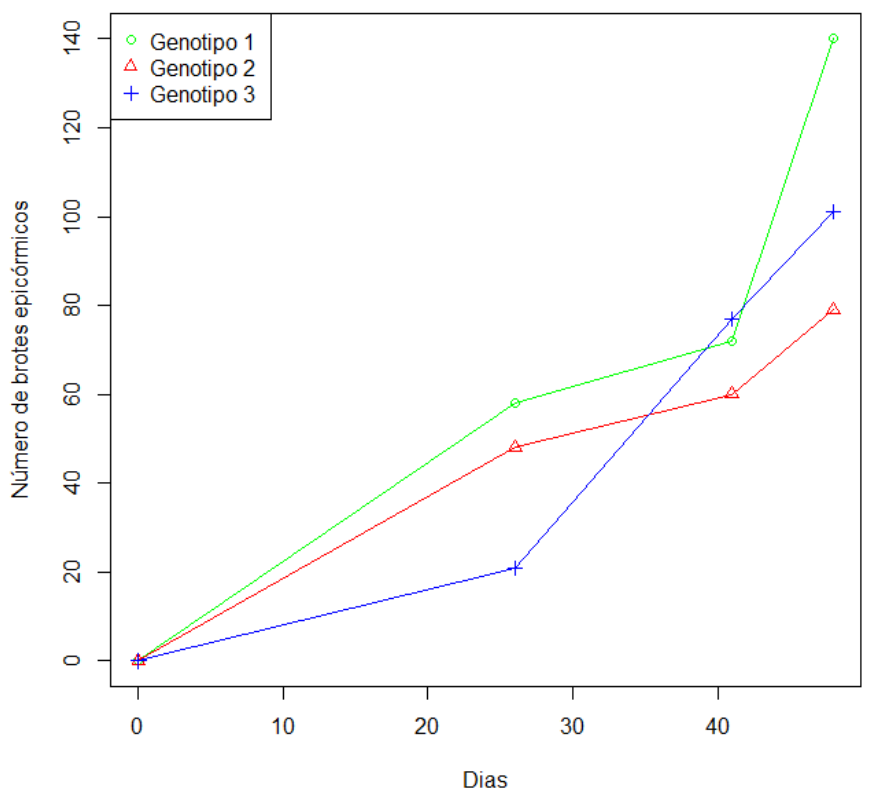

Figura $\mathrm{N}^{\circ} 4$

NÚMERO DE BROTES EPICÓRMICOS GENERADOS SEGÚN GENOTIPO.

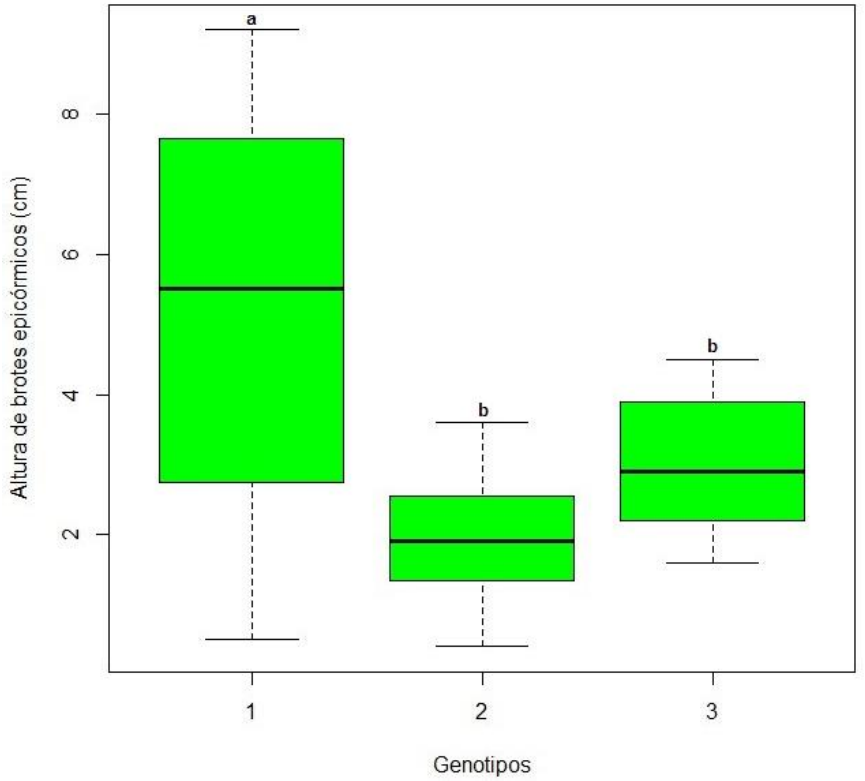

Letras distintas indican diferencias significativas (Tukey HSD, $\alpha=0.05$ ).

Figura $\mathrm{N}^{\circ} 5$

ANÁLISIS DE VARIANZA (ANOVA) DE LA ALTURA DE BROTES EPICÓRMICOS GENERADOS POR 3 GENOTIPOS 


\section{Establecimiento de Brotes}

Los brotes epicórmicos generados fueron utilizados como fuente de material para iniciación del cultivo en condiciones in vitro utilizando medios sin hormona (MS). Una vez realizado este proceso se evaluó la tasa de brotes contaminados y oxidados (TBC y TBO, respectivamente). Los resultados de este análisis muestran tasas muy bajas, el C1 exhibe un 6\% (TBC) y 3\% (TBO), para el C2 un $8 \%$ (TBC) y un 10\% (TBO), por ultimo para el C3, las tasas fueron $6 \%$ (TBC) y $4 \%$ (TBO).

La contaminación fue principalmente fúngica y la oxidación se presentó en las hojas de los brotes, y esto es común en algunas especies que presentan concentraciones elevadas de sustancias fenólicas (De Klerk et al., 2011; Trueman et al., 2013). Según Benson (2000) la oxidación impulsa el aumento de los radicales libres que son responsables del daño irreparable al ADN, a las proteínas y a las enzimas, causando la disfunción celular y la muerte de los explantes.

\section{Multiplicación de Brotes}

Las variables número de brotes nuevos (NBN) y número de hojas nuevas (NHN), fueron utilizadas para determinar la capacidad de multiplicación de los genotipos, con el fin de determinar el mejor tratamiento para multiplicación in vitro de boldo. La variable NBN fue transformada mediante la función $f(x)=1 / x$, que comprime los valores altos y expande los pequeños para ajustar normalidad. Los diferentes genotipos fueron comparados en el NBN al día 60 utilizando un análisis de varianza (ANOVA), esta prueba arrojó que existen diferencias significativas ( $\mathrm{F}=4.33, p$ valor $=0.002$ ), siendo los tratamientos T1 y T3, aquellos que presentan mayor NBN (Figura $N^{\circ} 6$ ).

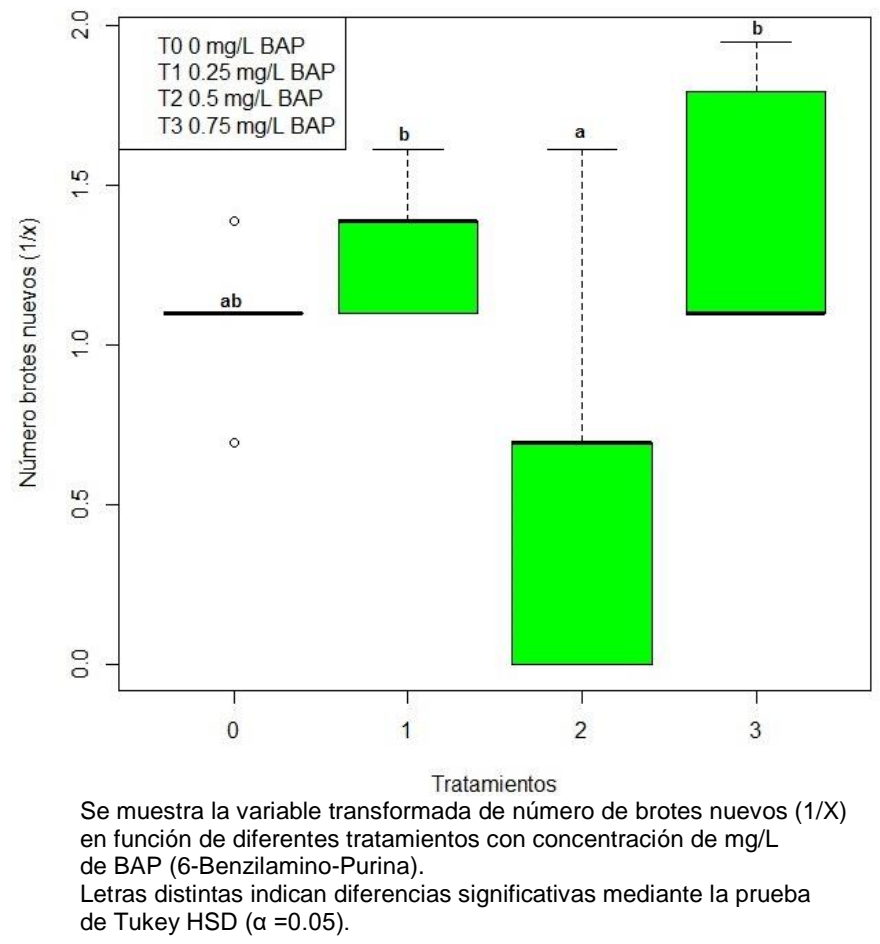

Figura $\mathrm{N}^{\circ} 6$

ANÁLISIS DE VARIANZA (ANOVA) DE 4 TRATAMIENTOS DE MULTIPLICACIÓN IN VITRO DE BROTES EPICÓRMICOS 
Así, el rango óptimo de concentración de BAP que asegura la multiplicación de los brotes fluctúa entre $0,25 \mathrm{mg} / \mathrm{L}$ y $0,75 \mathrm{mg} / \mathrm{L}$. Al respecto algunos autores registran que altas concentraciones iniciales de citoquininas estimulan la proliferación de múltiples puntos de crecimiento en tejido no meristemático, debido a su efecto en la división celular, a nivel de fase G1 y M del ciclo celular (Jordán y Casaretto, 2006), lo que podría explicar el alto NBN observado cuando se utilizó el T3 (Sánchez et al., 1997; Guohua, 1998; Read y Preece, 2003, Collado et al., 2004).

A medida que avanza la etapa de multiplicación, es decir en los subcultivos, se acostumbra disminuir gradualmente la concentración de la citoquinina para permitir la elongación de los nuevos brotes, tal como ha sido reportado para otras latifoliadas utilizando brotes epicórmicos (Sánchez et al., 1997; Rodriguez et al., 2003; Collado et al., 2004; Akram y Aftab, 2009; Castro y Sánchez, 2010).

Los datos obtenidos en este ensayo se asemejan con los obtenidos por Ríos et al. (2010) en boldo, quien determinó que el uso de una concentración de BAP en un rango de entre 0,5 y 1 $\mathrm{mg} / \mathrm{L}$, aumentó el número de brotes, utilizando como fuente de material segmentos nodales desde arboles adultos, los cuales son un material altamente lignificado y consecuentemente es de esperar requerimientos mayores en la concentración de BAP para activar la división celular de tejidos no meristemáticos. Como se observa en la Figura $\mathrm{N}^{\circ} 7$, de acuerdo al presente estudio, cuando se utiliza un material juvenil o revigorizado como el caso de los brotes epicórmicos, las concentraciones requeridas de BAP son menores, sin embargo, se continúa variando en un rango de 0,5 unidades $(\mathrm{mg} / \mathrm{L})$ de BAP. Se debe entonces considerar la fuente de material y la variación entre diferentes genotipos para establecer un protocolo de multiplicación in vitro de boldo (Sánchez-Olate et al., 2005; Koch et al., 2016).

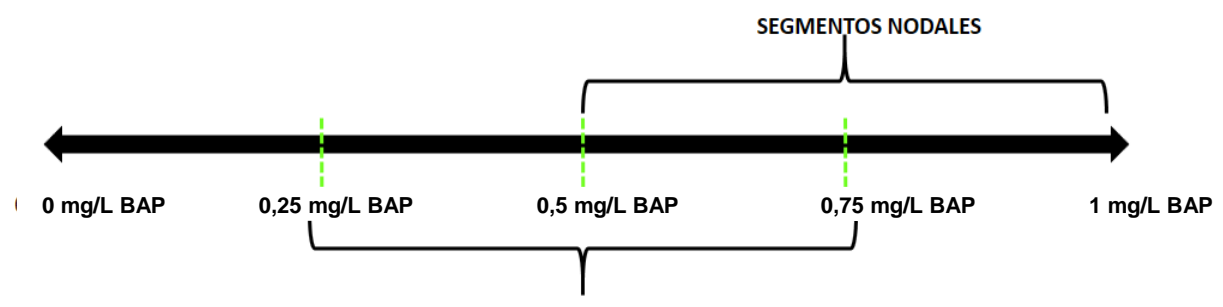

BROTES EPICORMICOS

Figura $\mathrm{N}^{\circ} 7$

ESQUEMA DE RANGOS DE CONCENTRACIÓN DE 6-BENZYLAMINOPURINE (BAP) EN LA MULTIPLICACIÓN IN VITRO DE BROTES NUEVOS SEGÚN FUENTE DE MATERIAL VEGETAL EN ARBOLES ADULTOS

En un sentido práctico y considerando que es un material juvenil y que no existen diferencias en los tratamientos T1 y T3, es más conveniente usar inicialmente T1 $(0,25 \mathrm{mg} / \mathrm{L}$ de $\mathrm{BAP})$, pero dependerá del comportamiento de los diferentes genotipos. Si la fuente del material es un material más adulto, se podría utilizar T3 $(0,75 \mathrm{mg} / \mathrm{L}$ de BAP) en una etapa inicial e ir disminuyendo gradualmente hasta T1, en función de la multiplicación y elongación de los brotes.

En relación a la variable NHN, no existen diferencias significativas entre los tratamientos $(\mathrm{F}=2,27, p$-valor $=0,12)$, sin embargo, hay una relación positiva ( $\mathrm{r}=0,77$, coeficiente de Spearman) entre las variables NBN y NHN. Estos resultados establecen antecedentes relevantes en la generación de un protocolo de multiplicación de material mediante micropropagación de boldo (Figura $\mathrm{N}^{\circ} 8$ ), dado que permite la generación de material base para la aplicación de nuevos tratamientos en las etapas posteriores, así como estudios de fisiología vegetal en la especie en estudio. 


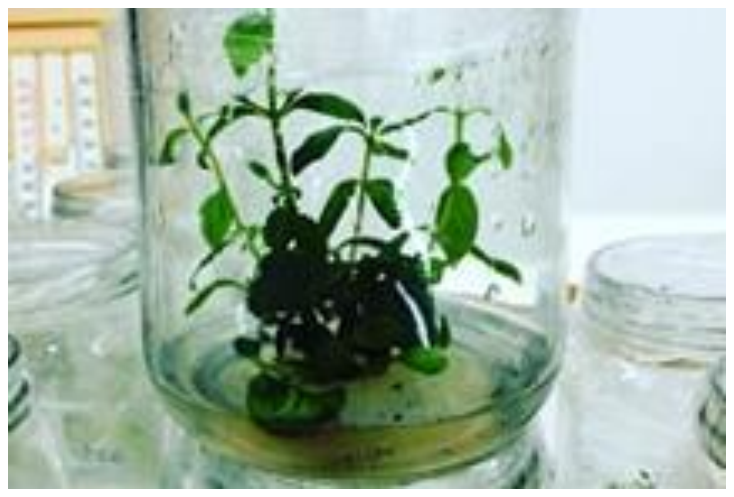

Figura $\mathrm{N}^{\circ} 8$

MULTIPLICACIÓN DE MATERIAL MEDIANTE MICROPROPAGACIÓN DE BOLDO MULTIPLICACION Y ELONGACION DE LOS BROTES

\section{Enraizamiento de Brotes}

Posterior a la etapa de multiplicación in vitro se seleccionaron los brotes homogéneos, vigorosos y sanos (Figura $\mathrm{N}^{\circ}$ 9) para la evaluación de la capacidad de enraizamiento, se probaron los diferentes tratamientos basados en concentraciones IBA. Las auxinas son hormonas que promueven el crecimiento o elongación de las plantas mediante dos vías; i) por incremento de la extensibilidad de la pared celular debido a la secreción de iones de hidrógeno dentro y a través de esta, permitiendo finalmente que las células se expandan debido a una mayor absorción de agua, y por un ii) efecto en el metabolismo del ácido ribonucleico (ARN), que induce posiblemente la trascripción de moléculas de ARN mensajero, las cuales codifican proteínas necesarias para el desarrollo de las plantas (Castro y Sánchez, 2010).

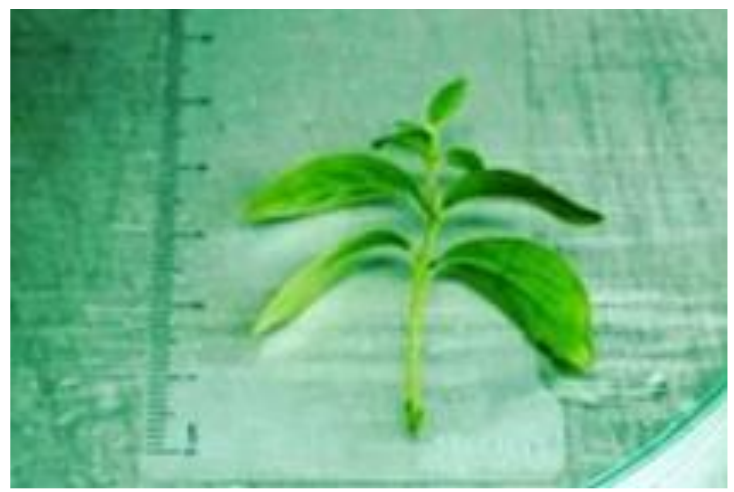

Figura $\mathbf{N}^{\circ} 9$

SEGMENTOS DE BROTES PROVENIENTES DE LA MULTIPLICACION DEL MATERIAL INCIAL

El ensayo de enraizamiento con auxinas se llevó a cabo solamente en el genotipo C3, ya que solo este mostro un desarrollo radicular, esto es común en la especie la cual se caracteriza por presentar una baja capacidad de enraizamiento (Jeldres, 1998), según Santelices y Bobadilla (1997) y Voguel et al. (2005) cercana al < 10\%, incluso utilizando material juvenil procedentes de rebrotes de tocón. 
A 60 días del montaje de este ensayo, se evalúo la capacidad de enraizamiento de los brotes de boldo como el número y longitud de raíces nuevas (NRN y LRN, respectivamente), se compararon los diferentes tratamientos utilizando un análisis de varianza (ANOVA). Los resultados obtenidos de esta medición muestran que existen diferencias significativas entre los tratamientos para la variable NRN $\left(F=13,35, p\right.$-valor $\left.=3 \times 10^{-7}\right)$ (Figura $\left.N^{\circ} 10\right)$, siendo los tratamientos $\mathrm{T} 1(0,5 \mathrm{mg} / \mathrm{L}$ IBA) y T2 (1 mg/L IBA) los que presentan la mejor capacidad de enraizamiento, por lo tanto, el uso de IBA en la etapa de enraizamiento de explantes de boldo debe estar en el gradiente de $0.5-1$ $\mathrm{mg} / \mathrm{L}$.

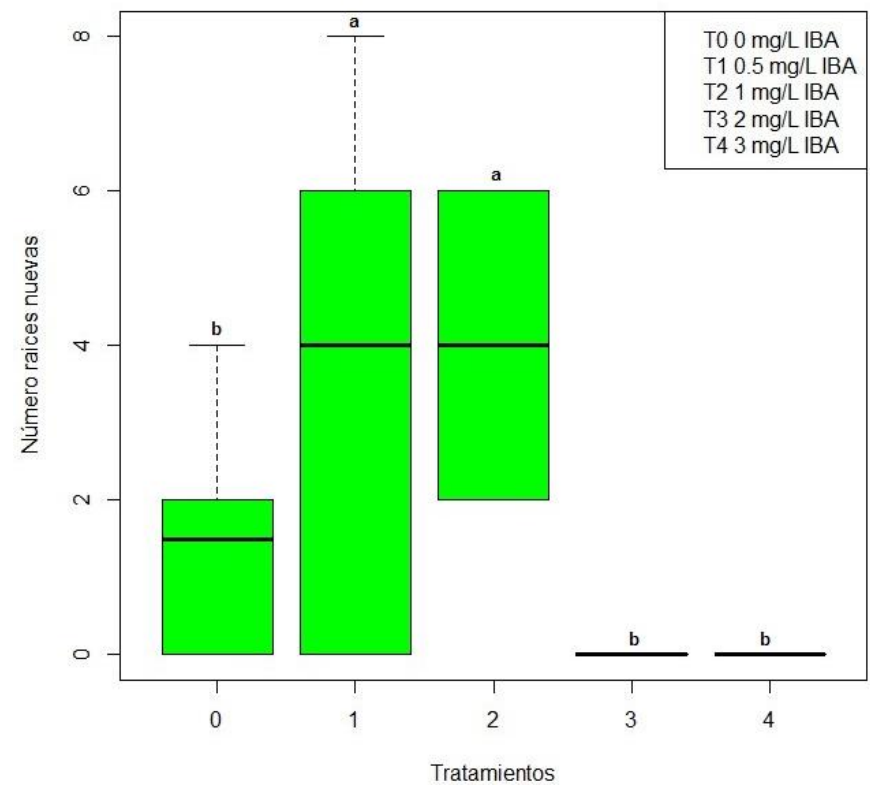

Se muestra la variable número de raíces nuevas en función de diferentes tratamientos con concentración de $\mathrm{mg} / \mathrm{L}$ de IBA (Ácido Indol-3-butírico). Letras distintas indican diferencias significativas mediante la prueba de Tukey HSD $(\alpha=0.05)$.

\section{ANÁLISIS DE VARIANZA (ANOVA) DE 5 TRATAMIENTOS DE ENRAIZAMIENTO IN VITRO DE BROTES EPICÓRMICOS}

Resultados similares se muestran en otros estudios de especies del bosque esclerófilo, tales como espino (Acacia caven) o quillay (Quillaja saponaria), donde se evidencia que las bajas concentraciones de auxinas aumentan el NRN (Albedini et al., 2000; Prehn et al., 2003). Para la variable LRN no hubo diferencias significativas entre los tratamientos $(F=0,121, p$-valor $=0,973)$

El hecho que en el tratamiento T0 (sin hormona) no se produjera enraizamiento de los brotes indica que es necesaria la aplicación de un estímulo hormonal exógeno para la formación de raíces en el material utilizado.

Es importante señalar que la rizogénesis ocurrió en forma bastante lenta, observándose emergencia de las primeras raíces $>30$ días. Durante este período no se observó necrosis apical de los explantes, esto se explica debido a que en plantas leñosas la organogénesis resulta más difícil de lograr por su condición estructural y los procesos de la madurez asociados con la edad.

Al respecto, se pueden mencionan tres etapas que explican lo anterior (Vidal et al., 
Envejecimiento cronológico: Referido a cambios expresados en función del tiempo.

Envejecimiento ontogénico: Relacionado a la transición gradual e irreversible regulada bajo control genético.

Envejecimiento fisiológico: Asociado con la pérdida de vigor causada por cambios hormonales, condiciones nutricionales y ambientales.

Es por ello que se utilizó como estrategia, la inducción de brotes epicórmicos, los cuales son ontogénicamente más jóvenes y ostentan una mejor respuesta morfogénica y fisiológica, debido a que han sido generados a partir de tejidos meristemáticos latentes (Sanchez-Olate et al., 2005; Hasbun 2006). Cabe mencionar que las variables NRN y LRN, no permiten establecer el mejor protocolo de enraizamiento per se, ya que la respuesta fisiológica de las raíces, es decir la capacidad de absorción de agua y nutrientes, pudiera tener incidencia en el crecimiento posterior de las plantas (etapa de aclimatación), pudiendo ser nulo incluso en brotes que poseen una gran cantidad de raíces. Por lo tanto, es necesario evaluar la evolución de las plantas, antes de seleccionar el procedimiento de enraizamiento definitivo.

Aunque los resultados de la etapa de enraizamiento son satisfactorios (Figura $\mathrm{N}^{\circ} 11$ ), es decir se genera una adecuada cantidad de raíces funcionales, se debe considerar que solo se ha utilizado 1 genotipo de boldo para hacer esta comparación, siendo este un resultado preliminar, por lo que para afirmar este supuesto se debe utilizar una mayor cantidad de genotipos, lo que es materia de investigaciones futuras.

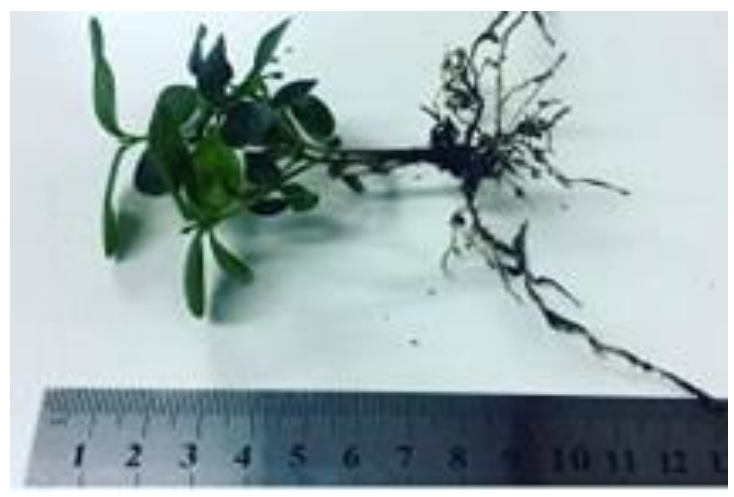

Figura $\mathrm{N}^{\circ} 11$

\section{ENRAIZAMIENTO DE BROTES MULTIPLICADOS IN VITRO}

El protocolo de aclimatación de las plantas fue satisfactorio, obteniéndose una supervivencia $>90 \%$ de los brotes cultivados (Figuras $\mathrm{N}^{\circ} 12$ y $\mathrm{N}^{\circ} 13$ ), cabe mencionar que la especie corresponde al grupo de especies semixeromórficas típicas del bosque esclerófilo (Schneeberger, 2001; Benedetti y Barros, 2011), es decir posee hojas perennes y duras, que les permiten resistir las sequías veraniegas y heladas de primavera, características del mediterráneo (Benedetti y Barros, 2011).

En el caso que las plantas regeneradas mediante organogénesis tuviesen destino este tipo de suelos y climas, se aconseja endurecer en vivero u invernadero antes de llevarse a plantación, con esto se garantiza que la planta sobrevivirá a las condiciones adversas propias de estos ambientes, tales como heladas tempranas, alta radiación y sequía. 


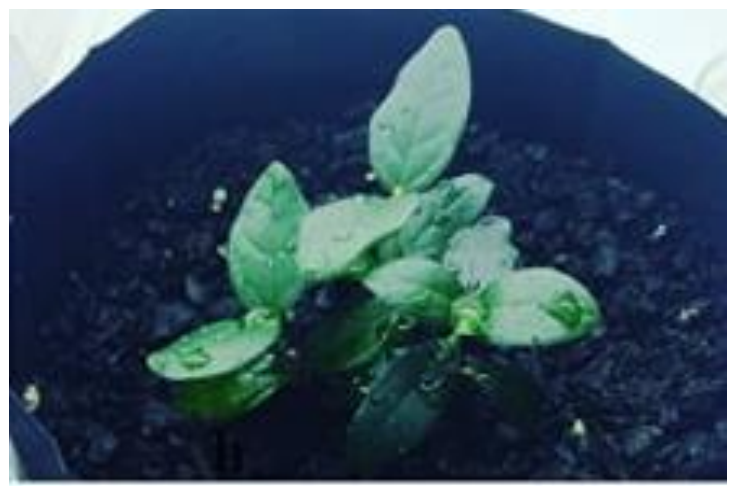

Figura $\mathrm{N}^{\circ} 12$

\section{ACLIMATACIÓN DE PLANTAS COMPLETAS}
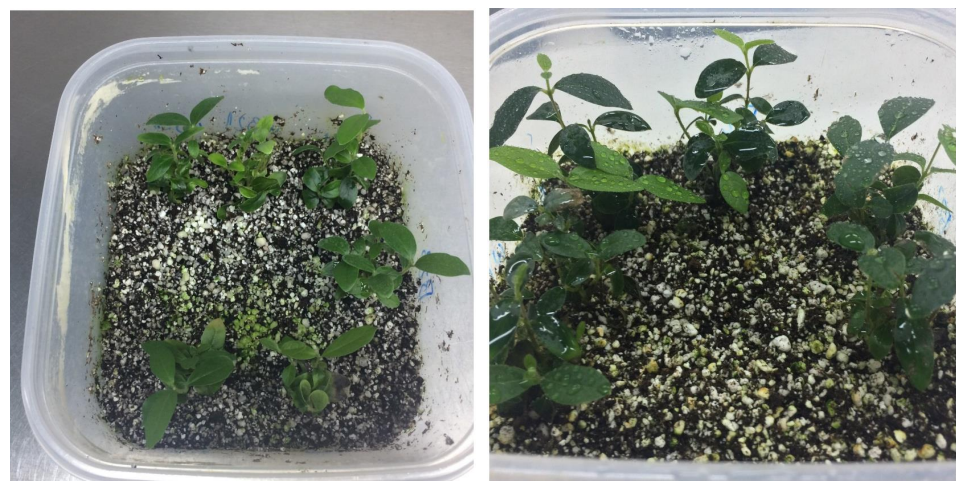

Figura $N^{\circ} 13$

PLANTAS CLONALES EN ETAPA DE ACLIMATACIÓN

REGENERADAS MEDIANTE ORGANOGENESIS

\section{CONCLUSIONES}

Los antecedentes presentados en este artículo describen una de las primeras aproximaciones a la clonación in vitro en árboles adultos de boldo y los resultados presentados muestran que es posible regenerar plantas completas mediante técnicas de micropropagación.

Dadas las limitaciones que tiene la especie para la reproducción vegetativa tradicional, como el estaquillado, estos resultados son de gran interés como una metodología de masificación de material selecto en estudios de fisiología vegetal y/o programas de mejoramiento genético en la especie.

Ante una demanda emergente de metabolitos y principios activos de origen natural, como lo es la boldina, esta metodología es un avance que puede sustentar programas y estudios como los mencionados tendientes a apoyar el manejo sostenible de la especie.

En futuras investigaciones de las características de la realizada se debe considerar mayor número de genotipos. 


\section{REFERENCIAS}

Abedini, W.; Boeri, P.; Marinucci, L.; Ruscitti, M. and Scelzo, L., 2000. Biotechniques used in native forest species. Forest Systems, 9(1), 31-43.

Akram, M. and Aftab, F., 2009. An efficient method for clonal propagation and in vitro establishment of softwood shoots from epicormic buds of Teak (Tectona grandis L.). Forestry Studies in China, 11(2): 105-110.

Benedetti, S. y Barros, S., (Eds). 2011. Boldo (Peumus boldus Mol.) Rescate de un patrimonio forestal chileno manejo sustentable y valorización de sus Productos. Instituto Forestal (INFOR).

Benson, E., 2000. Special symposium: In vitro plant recalcitrance. Do free radicals have a role in plant tissue culture recalcitrance? In Vitro Cell Dev Biol Plant 36(3):163-170

Borges, N.; Martins-Corder, M.; Sobrosa, R. y Santos, E., 2004. Rebrota de cepas de árvores adultas de acácia-negra (Acacia mearnsii De Wild.). Revista Árvore, 28: 611-615.

Castro, D. y Sanchez, R., 2010. Propagación clonal in vitro de Eucalyptus pellita F. Muell a partir de árboles plus. Temas Agrarios, 15:(1) $34-43$.

Collado, R.; Barbón, R.; Agramonte, D.; Jiménez, F.; Pérez, M.; Gutiérrez, O. y Ramírez, D., 2004. Establecimiento in vitro de ápices y segmento nodales de Swietenia macrophylla King. Biotecnología Vegetal, 4 (3): 143-146,

De Fossard A.; Broker, P. and Bourne, R., 1977. The organ culture of nodes of four species de Eucalyptus. Acta Horticulturae,78: 157-165.

De Klerk, G.; Guan, H.; Huisman, P. and Marinova, S., 2011. Effects of phenolic compounds on adventitious root formation and oxidative decarboxylation of applied indoleacetic acid in Malus 'Jork 9'. Plant Growth Regulation ,63(2):175-185

Durand-Cresswell, R.; Boulay, M. and Franclet, A., 1982. Vegetative propagation of Eucalyptus. En: Bonga J. and Dursan, D. (Eds). Tissue culture in forestry. Springer Science, 99: 150-181.

Espic, M., 2007. Evaluación de la producción de biomasa aérea y del rendimiento en aceite esencial y boldina, de Boldo (Peumus boldus Mol.) en la comunidad de Papudo, $\mathrm{V}$ región. Memoria para optar al título profesional de Ingeniero Forestal. Escuela de Ciencias Forestales, Facultad de Ciencias Forestales, Universidad de Chile. Santiago, Chile.

Fink, S., 1983. The Occurrence of Adventitious and Preventitious Buds within the Bark of Some Temperate and Tropical Trees. American Journal of Botany, 70: 532-542

Furze, M. and Cresswell, C., 1985. Micropropagation of Eucalyptus grandis and E. nitens using tissue culture techniques. African Journal of Agricultural Research, 135:20-23.

Franclet, A. and Boulay, M., 1982. Micropropagation of frost resistant Eucalypt clones. Australian Forest Research, 13: 83-89.

Goncalves, A., 1980. Reversion to juvenility and cloning of Eucalyptus urophylla S.T. Blake in cell and tissue culture systems. IUFRO Symposium and Workshop on Genetic Improvement and Productivity of Fast Growing Tree Species. Sao Paulo, Brazil. 786-787 pp.

Grewal, S.; Ahuja, A. and Atal, C., 1980. In vitro proliferation of shoot apices of Eucalyptus citriodora Hook. Ind. Journal of Experimental Biology, 18:775-777.

Guohua, M., 1998. Effects of cytokinins and auxins on Cassava shoot organogenesis and somatic embryogenesis from somatic embryo explants. Plant Cell, Tissue and Organ Culture, 54: 1-7.

Hartmann, H. y Kester, D., 1990. Propagación de plantas. Principios y prácticas. Compañía Editorial Continental, México. 760pp.

Hasbún, R., 2006. Monitorización Epi-genética del desarrollo y producción de plantas de castaño (Castanea sativa). Tesis Doctor en Biotecnología. Universidad de Oviedo. Oviedo, España. 234 p

Hernández, I.; Celestino, C. and Toribio, M., 2003. Vegetative propagation of Quercus suber L. by somatic embryogenesis. II. Plant regeneration from selected Cork Oak trees. Plant Cell Report, 21:765-770. 
Ikemori, Y., 1987. Epicormic shoots from the branches of Eucalyptus grandis as an explant source for in vitro culture. The Commonwealth Forestry Review, 66: 351-355.

Jeldres, P., 1998. Efecto del ácido Indolbutirico y época de colecta del material vegetal en el enraizamiento de estacas de Peumus boldus Mol. Memoria para optar al título profesional de Ingeniero Forestal. Escuela de Ciencias Forestales, Facultad de Ciencias Forestales, Universidad de Talca. Talca, Chile.

Jordán, M. y Casaretto, J., 2006. Hormonas y Reguladores del Crecimiento: Auxinas, Giberelinas y Citocininas. En: Squeo, F. y Cardemil, L. (Eds). Fisiología Vegetal. Ediciones Universidad de La Serena, La Serena, Chile

Koch, L.; Gonzalez, J.; Benedetti, S. and Molina, M. P., 2016. Generation of epicormics shoots for vegetative propagation in vitro Peumus boldus. Mol. Trabajo modalidad de poster presentado en la IUFRO Conferencia Internacional "Embriogénesis somática y otras tecnologías de propagación vegetativa". La Plata, Argentina.

Le Roux, J. and Van Staden, J., 1991. Micropropagation and tissue culture of Eucalyptus - a review. Tree Physiology, 9: 435-477

Mc Comb, J. and Bennett, I., 1986. Eucalyptus (Eucalyptus spp). En: Y.P.S. Bajaj (Ed). Biotechnology in Agriculture and Forestry, Volume 1: Trees 1. Springer-Verlag, Alemania. 340-362 pp.

Montenegro, G., 2000. Chile nuestra flora útil, Guía para Uso Apícola, Medicinal, Folclórica, Artesanal y Ornamental. Ediciones Universidad Católica de Chile, Santiago, Chile. 267pp.

Murashige, T. and Skoog, F., 1962. A revised medium for rapid growth and bioassays with Tobacco tissue cultures. Plant Physiology, 15: 473-497.

Oller, J.; Toribio, M.; Celestino, C. and Toval, G., 2004. The culture of elite adult trees in a genetic improvement programme through Eucalyptus globulus Labill. clonal micropropagation. Eucalyptus in a Changing World. Proc.of IUFRO Conf., Aveiro 11-15 Octuber 2004.

Ortiz, O.; Sabja, A. y Koch, L., 2006. Protocolo de micropropagación de Lenga. En: Gutiérrez, B. (Ed). Cultivo in vitro de Lenga (Nothofagus pumilio). INFOR. Chile. 76 pp.

Prehn, D.; Serrano, C.; Berrios, C. y Arce-Johnson, P., 2003. Micropropagación de Quillaja saponaria Mol. a partir de semillas. Bosque, 24(2), 3-12.

R Core Team. 2018. A language and environment for statistical computing. R Foundation for Statistical Computing, Vienna, Austria. URL http://www.R-project.org/.

Read, P. and Preece, J., 2003. Environmental Management for Optimizing Micropropagation. Acta Horticulturae, 616:49-58.

Ríos, D.; Sandoval, D. y Gómez, C., 2010. In vitro culture of Peumus boldus Molina via direct organogenesis. IDECEFYN vol 21 January-April 2010, 70-72.

Rodriguez, R.; Daquita, M.; Capote, I.; Pina, D.; Lezcano, Y. y González-Olmedo, J., 2003. Nuevos aportes a la micropropagación de Swietenia macrophylla x Swietenia mahogani (Caoba híbrida) y Cedrela odorata (Cedro). Cultivos Tropicales, 24 (3):23-27

Sabja, A.; Ortiz, O. y Triviño, C., 2005. Micropropagación de árboles plus de raulí. En: Gutiérrez, B., Ortiz, O., Molina, M. (Ed). Clonación de raulí, estado actual y perspectivas. CEFOR, INFOR, UACH. 41-58 pp.

San Martín, J. y Doll, U., 1998. Peumus boldus Mol. (Monimiaceae, Magnoliopsida) una especie silvestre promisoria de Chile. Botanical Studies, 17:109-118.

Sánchez, M.; San-Jose, M. and Ballester, Vieitez, 1996. Requirements for in vitro rooting of Quercus robur and Q. rubra shoots derived from mature trees. Tree Physiology 16(8):673-80.

Sánchez, M.; San-Jose, M.; Ferro, E.; Ballester, A. and Vieitez, A., 1997. Improving micropropagation conditions for adult-phase shoots of Chestnut. Journal of Horticultural Science, 72(3): 433-443

Sánchez-Olate, M.; Ríos, D. y Escobar, R., 2005. La Biotecnología Vegetal y el Mejoramiento Genético de Especies Leñosas de Interés Forestal y sus Proyecciones en Chile. In: Sánchez-Olate, M. y Ríos, D. (Eds.). Biotecnología Vegetal en Especies Leñosas de Interés Forestal. Departamento de Silvicultura. Facultad de Ciencias Forestales. Universidad de Concepción. Concepción, Chile. pp. 17-28.

Santelices, R. y Bobadilla, C., 1997. Arraigamiento de estacas de Quillaja saponaria Mol. y Peumus boldus Mol. 
Bosque 18(2):77-85.

Schneeberger, R., 2001. Efecto de poda invernal e intensidad de luz sobre el crecimiento y concentración de principios activos en boldo (Peumus boldus Mol.) bajo cultivo. Memoria para optar al título profesional de Ingeniero Forestal. Universidad de Talca. Talca, Chile.

Trueman, S.; Mc Mahon, T. andBristow, M., 2013. Nutrient partitioning among the roots, hedge and cuttings of Corymbia citriodora stock plants. Journal of Soil Science and Plant Nutrition, 13(4):977-989

Vidal, J.; Ríos, D.; Sabja, A.; Cartes, P. y Sánchez Olate, M., 2016. Organogénesis directa para la propagación in vitro de Quillaja saponaria Molina en Sudamérica Austral. Revista Mexicana de Ciencias Forestales, 7(34):5768.

Vogel, H.; Rasmilic, I.; San Martín, J.; Doll, U. y González, B., 2005. Plantas medicinales chilenas. Experiencias de domesticación y cultivo de Boldo, Matico, Bailahuén, Canelo, Peumo y Maqui. Editorial Universidad de Talca, Chile. 194pp.

Yara, K., 1987. Epicormic shoots from the branches of Eucalyptus grandis as an explant source for in vitro culture. The Commonwealth Forestry Review, 66 (4):351-356. 
